\title{
Prevenção da violência conjugal contra a mulher
}

\author{
Prevention of conjugal violence against women
}

Mara Aparecida Alves Cabral 1

\footnotetext{
1 Departamento de Psicologia Clínica e Psiquiatria, Faculdade de Ciências Médicas, Universidade Estadual de Campinas, Cidade Universitária Zeferino Vaz, Caixa Postal 61111, 13083-970 Campinas, SP, Brasil.
}

Abstract The basic purpose of this study was to perform a review of the medical, psychological, psychiatric, and sociological literature on wife battering. The article provides a critical analysis of the preventive measures adopted by countries with high human development indices, like Canada and France, based on the efficacy of such measures. It compares this application with that currently being conducted in Brazil. The methodology involved a search of the pertinent literature, especially from the last ten years, from such countries as England, the United States, Canada and France. These countries have the world's best organized services to aid women who have suffered domestic violence and their aggressors. They are also the countries with the most publications on this specific issue. Several Brazilian articles were chosen to situate the issue within our context. Preventive measures like expanding telephone hot lines, organizing shelters for emergency situations, reducing social tolerance of violent acts, increasing penalties, and providing legal aid and treatment for the parties involved are quoted in numerous studies approaching prevention of wife battering.

Key words Violence; Spouses; Women; Family
Resumo Este trabalho visa a realizar uma revisão bibliográfica da literatura médica, psicológica, psiquiátrica e sociológica, concernente ao combate à violência conjugal contra a mulher. Analisa criticamente as medidas preventivas propostas em países com alto indice de desenvolvimento humano, como é o caso do Canadá e da França, tomando por base a aplicabilidade e eficácia dessas medidas. Compara esta aplicação com o que é realizado no Brasil neste momento. Levanta a bibliografia, principalmente destes últimos dez anos, selecionando artigos de países como a Inglaterra, Estados Unidos, Canadá e França. Estes países possuem os serviços de atenção às vítimas de violência conjugal, assim como de seus agressores, mais estruturados e bem equipados do mundo.Têm também um maior volume de publicações sobre este assunto específico. Selecionaram-se alguns artigos brasileiros para situar melhor a questão no país. Medidas preventivas como a ampliação de redes telefônicas de ajuda; a implantação de casas-abrigo em situações emergenciais; a redução da tolerância social aos atos de violência, aumentando as penalidades; a assistência jurídica e terapêutica aos envolvidos, são citadas em inúmeros trabalhos que abordam a prevenção da violência conjugal contra a mulher.

Palavras-chave Violência; Cônjuges; Mulheres; Família 


\section{Introdução}

A violência do homem contra a mulher, com a qual convive em regime conjugal, representa um problema psicossocial e jurídico de extrema importância nos dias atuais, pois suas conseqüências afetam além dos elementos das famílias envolvidas, também a economia do país e a sociedade de forma geral (Azevedo, 1985; Rosen 1989; Beissman, 1994; Veja, 1998; Folha de São Paulo, 1998a,b,c). Portanto, a luta contra este tipo de violência concerne a todos nós e, principalmente, aos governantes, a quem cabem medidas efetivas para ajudar a combater e prevenir, de forma eficaz, estes atos.

O fenômeno da violência conjugal ocorre em todos os níveis sócio-econômicos, sobretudo naqueles de baixa renda, pelo fato de que as dificuldades financeiras, a miséria e as desestruturações familiares, favorecem o clima de instabilidade no humor, exacerbando os comportamentos agressivos nos indivíduos (Lystad, 1975; Prado \& Oliveira, 1982; Oliveira et al., 1984; Azevedo, 1985).

A conscientização de que a violência praticada contra a mulher é absurda e deve ser erradicada, começou em nosso país, como na maior parte do mundo civilizado, a partir da luta das feministas, que saíram às ruas, principalmente na décadas de 70 e 80 , gritando contra a impunidade dos agressores nos denominados "crimes da paixão" (Chesnais, 1981; Azevedo, 1985; Beissman 1994).

Esse trabalho de conscientização junto aos meios de comunicação e à sociedade em geral, carreou consigo a abordagem de que os espancamentos de mulheres devem ser percebidos como um problema social e de saúde pública, não apenas por suas proporções numéricas, mas também pela gravidade de suas conseqüências psicofísicas. Com isto conseguiu-se, junto ao Estado, a criação de órgãos específicos no combate a este tipo de violência, como as Comissões de Defesa dos Direitos da Mulher, os Conselhos da Condição Feminina e o pioneirismo na criação das Delegacias Especializadas em atendimentos de mulheres agredidas (Azevedo, 1985; Silva, 1992; Beissman, 1994).

Sabemos que desde a Idade Média, os maus-tratos infligidos às mulheres eram tolerados e até enaltecidos como práticas cujos propósitos eram corrigi-las de suas manhas e erros. Porém, já no século XV, começam a ser registrados protestos e mudanças no comportamento jurídico em punir e condenar os ma- ridos que agissem com extrema brutalidade e violências graves contra suas esposas. No final do século XVIII e meados do século XIX, é visível um retrocesso nestas práticas, principalmente na Inglaterra e Estados Unidos (Chesnais, 1991; Beissman, 1994).

Dados históricos sobre o Brasil, na época colonial, revelam que já na Ordenação do Reino, era permitido aos maridos "emendarem" suas companheiras, pelo uso da chibata (Azevedo, 1985; Beissman, 1994). Portanto, as agressões físicas e psicológicas contra as mulheres fazem parte de nossas raízes culturais, trazidas pelos colonizadores europeus e reforçadas no século passado pelas idéias do positivismo de Auguste Comte (1798-1857), para o qual a mulher deveria ser submissa, altruísta, desprovida de desejo sexual. Suas funções seriam de servir a seus maridos e filhos, dedicando-se exclusivamente às tarefas domésticas, em que pudessem manifestar seus dons maternais (Hahner, 1978). Sabemos que um grande número de agressões contra mulheres no meio doméstico, ocorre justamente quando estas decidem trabalhar fora de casa, ou quando ousam manifestar seus pontos de vista contrários aos seus maridos, contestando regras que ainda predominam em nosso meio.

Dados recentes nos mostram que $23 \%$ das mulheres brasileiras estão sujeitas à violência doméstica, segundo levantamento da "Sociedade Mundial de Vitimologia", sediada na Holanda. Constatamos também que $41 \%$ dos homens que espancam suas esposas, são violentos com os seus filhos; um terço destas crianças tende a reproduzir a agressividade contra si e contra outros quando crescem. Portanto, este ciclo de sofrimento vai se refletir, de forma massacrante e crescente, nas ruas de nossas cidades, pois a maioria das histórias de vida de presidiários (Cabral, 1990) relatam estas tristes ocorrências em suas infâncias e na relação diária com suas companheiras (Cabral, 1990; Veja, 1998).

Dados estatísticos nos revelam que em 1997, no Rio de Janeiro, registraram-se 5.098 ocorrências de violência doméstica por mês, ou seja, 170 novos casos de agressões por dia. Isso significa que a cada hora, há sete mulheres em situação de violência, segundo relatório do Conselho Estadual dos Direitos da $\mathrm{Mu}-$ lher. Em 1998, estes dados só vem aumentando (Veja, 1998).

Em Campinas, São Paulo, cidade com quase 1 milhão de habitantes, o Grupo SOS-Ação 
Mulher e Família, registrou no ano de 1998, até meados de setembro, 177,2 casos de violência contra a mulher por mês, contra a média de 71,5 no ano passado (Folha de São Paulo, 1998b).

Estas ocorrências acabam refletindo no Sistema de Saúde Pública e na economia dos países, pois estima-se que um em cada cinco dias de absenteísmo no trabalho feminino decorre da violência doméstica. Ela custa a países desenvolvidos, como o Canadá, 1,6 bilhão de dólares ao ano, somando-se os gastos de atendimentos médicos e queda da produtividade. Nos Estados Unidos, segundo o BID (Banco Interamericano de Desenvolvimento), estes gastos oscilam entre 10 a 60 bilhões de dólares por ano, dependendo dos critérios de englobamento dos gastos. No Chile, a violência contra mulher consome cerca de $2 \%$ do PIB (Produto Interno Bruto). No Brasil, os gastos não são menores (Veja, 1998).

De posse destes dados, o questionamento que fazemos é: sobre o que favorecem estas agressões do homem contra a mulher e, viceversa? Ao analisarmos a complexa trama de causalidades destas ocorrências, destacamos alguns fatores que podem colaborar em nossas reflexões. Estes fatores podem ser agrupados em: biológicos, psicológicos e sócio-culturais (Lystad, 1975; Oliveira et al., 1984; Silva, 1989; Rosen, 1989; Remschmidt et al., 1991; Beissman 1994).

Dentre os aspectos biológicos, além da predisposição genética ao temperamento violento, muitos pesquisadores têm correlacionado a agressividade e a violência, com uma desregulação no sistema límbico (Lystad, 1975; Cabral, 1990; Beissman, 1994; Kaplan \& Sadock, 1998). Observou-se que na ablação da amígdala cerebral, ocorrem significativas modificações de conduta, com redução do temor, da agressividade, além de alterações nos hábitos de ingestão de água e de alimentos. A ação de neurotransmissores, como a serotonina, dopamina, adrenalina, poderia estar relacionada com alterações do comportamento, pois servem como mediadores de funções cerebrais importantes, como a alegria, a depressão, a ira, etc. A adrenalina é um mediador utilizado nos estados de luta e de sobrecargas psicofísicas estressantes. O aumento de dopamina pode levar à inquietude, à ansiedade persecutória e a atitudes de agressividade e violência.

A atuação de alguns hormônios (Lystad, 1975; Cabral, 1990; Beissman, 1994; Kaplan \&
Sadock, 1998) como a testosterona no homem e o estrógeno e progestágenos na mulher, também parece ter importância nas alterações de humor e de comportamentos nos indivíduos mais predispostos às atitudes agressivas. Ilustrando isto, verificamos uma labilidade afetivo-emocional na mulher, principalmente durante o período pré-menstrual.

Quanto aos aspectos psicológicos (Carmichael, 1975; Silva et al., 1982; Wilson, 1985; Beissman, 1994), tem sido ressaltada a importância do ambiente familiar no equilíbrio do comportamento das crianças e adolescentes e, portanto, dos futuros adultos. A família fornece a matriz dentro da qual o indivíduo é moldado e se desenvolve; é o cerne para que ligações emocionais mais fortes sejam formadas; é o primeiro grupo dinâmico ao qual a criança é exposta e, nele, ela tem suas primeiras experiências e transações interpessoais. Quando ela é perturbada, fornece identificações e experiências de aprendizado patológicas. Logo, as atitudes e comportamentos dos pais, assim como a saúde física e mental destes, têm um impacto decisivo no ajustamento psicossocial de um filho.

Bowlby (1985a,b, 1990) e Winnicott (1987, 1989), enfatizam a importância e a influência, sobre o comportamento de uma criança, das experiências de perda por que estas podem passar precocemente. Estes autores ressaltam que a maneira como estes fatos lhes são passados, a relação da criança com o genitor que se foi, a reação do genitor sobrevivente, e como ele espera que a criança reaja a esta perda, podem ser cruciais no desenvolvimento emocional desses filhos. Para estes autores, uma criança que é separada dos pais em fase precoce de seu desenvolvimento, principalmente antes dos cinco anos, tem grande probabilidade de desenvolver transtornos psicossomáticos e/ou anti-sociais.

Dentre os aspectos psicossociais, têm sido salientadas as questões ligadas à pobreza, (embora exista violência em todas as classes sociais), ao excesso de pessoas residindo num mesmo ambiente, à falta de privacidade das aglomerações humanas, à migração do campo para as grandes cidades, à divisão de espaço e tarefas entre homens e mulheres, ao desemprego e ao alcoolismo (Cabernite, 1982; Rosen, 1989; Cabral, 1990; Cardin \& Azevedo, 1991), como fatores precipitadores de conflitos. É importante frisar que todos estes fatores, isoladamente, não explicam a atuação vio- 
lenta, e que a maioria dos trabalhos sobre violência doméstica não analisa profundamente a "relação psicodinâmica conflituosa" existente no lar do agressor e da mulher vitimada, principalmente quando sabemos que nem sempre a mulher agredida é apenas vítima pacífica nas relações com seus companheiros. Embora a agressão não se justifique em hipótese alguma, um trabalho preventivo deve visar a abordagem da relação estabelecida no dia-a-dia destes casais violentos.

Do exposto acima depreendemos que a violência traz conseqüências que podem ser dramáticas à saúde psicofísica dos envolvidos. $\mathrm{Na}$ maioria das mulheres vítimas da violência doméstica detectamos sinais e sintomas depressivos e ansiosos, perturbações do sono (hipersomnia e insônia), transtornos alimentares como a anorexia, a bulimia, a compulsão para comer, que favorece a obesidade, fobias de vários objetos, dificuldades sexuais, manifestações psicossomáticas como taquicardia, dores no peito, hipertensão arterial, crises asmáticas, dispepsias, colites, úlceras, síndrome do intestino irritável, sangramentos uterinos, dores pélvicas, dores osteo-musculares, além de quedas imunitárias, com maior predisposição à infeçções bacteriana e viral. Tem sido ressaltada também, uma maior incidência de alcoolismo, tabagismo e uso abusivo de calmantes entre estas mulheres (Lystad, 1975; Silva et al., 1982; Oliveira et al., 1984; Beissman, 1994; Raynor-Rinfret et al., 1994; Sharp et al., 1994; Folha de São Paulo, 1998, b, c, d).

Desta forma, os gastos com a saúde física e mental das vítimas da violência são enormes. Refletindo sobre a gravidade deste problema, nos indagamos: como poderemos coibir estas ocorrências? Que medidas preventivas poderíamos tomar para diminuir e evitar estes atos? A prevenção representa o eixo mais importante para reduzir e exterminar estas agressões. Ela pode ser realizada às custas de educação, pesquisas e serviços de assistência eficazes (Remschmidt et al., 1991; Ministère de Securité Publique, 1993; Ministère de la Justice, 1993, 1996; Ministère du Travail e des Affaires Sociales, 1996). Pensando nestes aspectos, passaremos a falar dos objetivos deste trabalho.

\section{Objetivos deste estudo}

Realizar uma revisão bibliográfica da literatura médica, psicológica e sociológica, concernente à prevenção à violência conjugal contra a mulher, em livros e artigos de língua inglesa e francesa.

Analisar criticamente as medidas preventivas propostas nestes trabalhos, tomando por base a aplicação e eficácia destas medidas, em países com índice de desenvolvimento humano elevados, como é o caso do Canadá e da França, comparativamente ao que é realizado no Brasil.

\section{Método deste estudo}

Para realizarmos um estudo crítico sobre as medidas preventivas relacionadas à violência conjugal contra a mulher, nos propusemos a fazer uma revisão bibliográfica sobre este assunto, principalmente dos últimos dez anos, em livros e revistas especializadas, que abordam esta temática (Lystad, 1975; Oliveira et al., 1984; Silva, 1989; Rosen, 1989; Remschmidt et al. 1991; Ministère de la Securité Publique, 1993; Ministère de la Justice, 1993, 1996; Raynor-Rinfret et al., 1994; Beissman, 1994; Sharp et al., 1994; Ministère du Travail et des Affaires Sociales, 1996).

Devemos salientar que os artigos que tratam deste tema específico não são numerosos, e que nenhum deles apresenta uma avaliação do acompanhamento e dos resultados psicossociais obtidos na aplicação destas medidas, ao longo dos últimos anos. Isto se deve ao fato que o tema violência na literatura especializada (médica, psicológica, psiquiátrica e sociológica) é recente, e passou a ser mais marcante há apenas quinze anos; também porque os estudos relacionados a este assunto se reportam mais a constatações clínicas de vítimas e agressores do que a outras comprovações, conforme assinalou Madame Marie Richardson, da Universidade de Québec, em conferência no último Congresso Mundial de Psiquiatria Social, realizado em Vancouver, no Canadá, em agosto de 1998.

Das revistas e livros que pesquisamos, no Index Medicus Internacional, incluindo o Latino-Americano, na Bireme, na Internet, em livrarias especializadas na área psicológica, sociológica, psiquiátrica e jurídica, selecionamos aqueles que tratam das medidas preven- 
tivas em países como França, Canadá, Inglaterra e Estados Unidos, por terem serviços melhor estruturados, com equipes assistenciais multidisciplinares, de mediação de casais, etc. (Lystad, 1975; Silva, 1989; Rosen, 1989; Remschmidt et al., 1991; Ministère de la Securité Publique, 1993; Ministère de la Jusstice, 1993, 1996; Raynor-Rinfret et al., 1994; Ministère du Travail et des Affaires Sociales, 1996).

Estes países são também aqueles que têm dado maior colaboração bibliográfica ao tema violência conjugal e violência doméstica, de forma geral.

Citamos algumas referências bibliográficas brasileiras, particularmente trabalhos realizados no estado de São Paulo, para situar melhor a questão dentro de uma realidade mais próxima à nossa (Oliveira et al., 1984; Azevedo, 1985; Beissman, 1994).

\section{A prevenção, segundo alguns autores}

Em linhas gerais, ela deve visar duas etapas principais (Ministère de la Segurité Publique, 1993; Ministère de la Justice, 1993): a) o ataque às causas dos conflitos, para se evitar agressões futuras e deter os danos causados a estas pessoas; b) favorecer a qualidade de vida dos indivíduos e da população, como forma de promover uma melhora substancial das relações estabelecidas no seio da família e também fora dela. Portanto, ela deve visar alguns objetivos fundamentais, como:

1) favorecer que as novas gerações adotem modelos relacionais fundamentados no respeito aos direitos das pessoas, nas responsabilidades individuais e no respeito às diferenças. Isto deve começar em casa e nas escolas, precocemente, através de medidas educativas (Remschmiddt et al., 1991; Ministère de la Segurité Publique, 1993; Ministère de la Justice, 1993, 1996; Ministère du Travail et des Affairs Sociales, 1996);

2) favorecer o estabelecimento de relações mais equalitárias entre os homens e as mulheres, incentivando divisões de tarefas domésticas, divisões nas responsabilidades financeiras da família, salários iguais para homens e mulheres que exerçam funções similares, abolição de fatores educacionais que reforçam que o homem deve ser sempre o mais forte emocionalmente (que nunca deve chorar ou demonstrar fragilidades), etc. (Ministère de la
Segurité Publique, 1993; Ministère de la Justice, 1993);

3) melhorar as condições de vida, atenuando as grandes diferenças de renda; melhoria das condições de trabalho no campo, para diminuir a migração para as grandes cidades; melhoria das condições de habitação; promoção de áreas de lazer para crianças e adolescentes; promoção e desenvolvimento de oficinas de especialização em áreas diversas de trabalho, para adolescentes e adultos (Ministère de la Segurité Publique, 1993; Ministère de la Justice, 1993, 1996; Ministère du Travail et des Affairs Sociales, 1996);

4) mobilizar todos os recursos para que a prevenção à violência seja uma prioridade nacional, estadual e municipal. Criar redes telefônicas onde as pessoas concernentes a estes problemas, possam recorrer em situações emergenciais, ou mesmo para elucidação de organismos que possam lhes dar assistência (Oliveira et al., 1984; Remschmidt et al., 1991; Ministère de la Segurité Publique, 1993; Ministère de la Justice, 1993; Raynor-Rinfret et al., 1994; Ministère du Travail et des Affairs Sociales, 1996);

5) promover cursos e conferências, orientando os médicos ginecologistas, pediatras, plantonistas de serviços de emergências, para diagnosticarem e notificarem as "síndromes da criança e da mulher espancadas". Promover cursos também para policiais e juízes (Ministère de la Segurité Publique, 1993; Ministère de la Justice, 1993, 1996; Ministère du Travail et des Affairs Sociales, 1996);

6)formar, nas sociedades de bairros carentes e em zonas rurais, líderes comunitários que possam intervir nas emergências, e que possam contactar ajuda em locais mais desenvolvidos e equipados para atenderem estas famílias (Ministère de la Segurité Publique, 1993; Ministère de la Justice, 1993);

7) reduzir a tolerância social à violência em geral e à doméstica em particular, obrigando as notificações, e aumentando as penalidades (Ministère de la Segurité Publique, 1993; Ministère de la Justice, 1993);

8) agir mais efetivamente em situações de risco aumentando número de SOS família, de conselheiros comunitários e espirituais; ajudando as mulheres, crianças e adolescentes, que vivem em situações de risco, através de visitas domiciliares constantes, oferecendo ajuda psicológica e jurídica a estes; oferecendo ajuda aos homens e mulheres violentos 
(Remschmidt et al., 1991; Ministère de la Segurité Publique, 1993; Ministère de la Justice, 1993, 1996; Ministère du Travail et des Affairs Sociales, 1996);

9) dar especial atenção a mulheres idosas, mulheres que apresentam deficiências físicas e psicológicas, a mulheres e familiares de presidiários e ex-presidiários, aos migrantes, aos homossexuais, e a todos aqueles que são concernentes ao problema da violência doméstica (Ministère du Travail et des Affairs Sociales, 1996);

10) afastar do lar, em abrigos provisórios, crianças, adolescentes e mulheres vitimadas, em situações de risco de agressões mais graves, cujas intervenções de ajuda no seio da família já tenham se esgotado (ou sejam impossíveis). Favorecer, dando subsídios para estas pessoas irem para outras localidades, longe dos seus agressores, em abrigos com assistência médica, social e psicológica (Oliveira et al., 1984; Silva, 1989; Rosen, 1989; Remschmidt et al., 1991; Ministère de la Segurité Publique, 1993; Ministère de la Justice, 1993, 1996; Raynor-Rinfret et al., 1994; Ministère du Travail et des Affairs Sociales, 1996);

11) assegurar a continuidade das ações e dos serviços oferecidos (Ministère du Travail et des Affairs Sociales, 1996);

12) dar assistência jurídica às vítimas, através de advogados e assistentes sociais eficazes, rápidos e interessados nos problemas. Encorajar as vítimas a pedirem ajuda judiciária e, conseqüentemente, a reduzirem as taxas de abandono dos processos criminais (Silva, 1989; Rosen, 1989; Ministère de la Segurité Publique, 1993; Ministère de la Justice, 1993; Raynor-Rinfret et al., 1994);

13) responsabilizar penalmente os agressores por seus atos (Ministère de la Segurité Publique, 1993; Ministère de la Justice, 1993; Ministère du Travail et des Affairs Sociales, 1996);

14) dar formação continuada aos profissionais que atuam nos diversos setores de auxílio às vítimas e aos agressores. Estas condições devem estar apoiadas em pesquisas que permitam melhorar os conhecimentos sobre o problema. Estas pesquisas devem também avaliar sistematicamente os serviços e os programas de ajuda, a fim de fornecer subsídios para ajustá-los e melhorá-los (Oliveira et al., 1984; Silva, 1989; Remschmidt et al., 1991; Ministère de la Segurité Publique, 1993; Ministère de la Justice, 1993; Raynor-Rinfret et al., 1994);
15) sensibilizar pessoas que possam intervir em setores privados (empresas), escolas, na comunidade, no judiciário, no meio policial, no correcional, assim como junto aos profissionais de saúde, para que possam contribuir, dentro dos limites de suas responsabilidades respectivas, na luta contra a violência doméstica (Ministère de la Segurité Publique, 1993; Ministère de la Justice, 1993);

16) sensibilizar os governantes sobre a incidência, gravidade e descaso para com estes problemas;

17) sensibilizar a mídia sobre a gravidade do problema.

No plano da Psicologia e da Psiquiatria Social, a prevenção deve: a) detectar patologias que favoreçam alterações no humor e possíveis atos de agressividade e violência, como: distimias, alterações ciclotímicas do humor (transtornos afetivos bipolares e unipolares, particularmente a hipomania); epilepsias de foco temporal, com alterações do comportamento; esquizofrenias, particularmente a paranóide, que evolui com delírios persecutórios; alcoolismo e abuso de outras drogas psicoestimulantes, como cocaína, crack, psilocibina (Cabernite, 1982; Caardein \& Azevedo, 1991; Beissman, 1994; Kaplan \& Sadock, 1998); b) dar especial atenção a uma história de vida bem feita, principalmente às particularidades das relações familiares na infância, às relações no trabalho, no trânsito, às relações com os cônjuges; prestar atenção também aos dados coletados na anamnese de indivíduos que praticam esportes considerados violentos ou de impacto, como a prática de artes marciais, por exemplo (Ministère du Travail et des Affaires Sociales, 1996); c) ao exame físico, pesquisar a presença de manchas roxas pelo corpo, cicatrizes, dores pélvicas, muito referidas por mulheres vitimadas sexualmente (Ministère du Travail et des Affaires Sociales, 1996); d) em caso de detectarmos violência doméstica, escutar atentamente a vítima e o agressor. Devemos facilitar a ambos a verbalização dos conflitos desencadeantes dos atos agressivos; devemos facilitar que os membros da família se reúnam e conversem sobre suas dificuldades de relacionamento, assim como sobre as alternativas para resolverem a estas dificuldades, sem se agredirem e sem se imporem mais sofrimentos.

Somente através de medidas efetivas, multidisciplinares e multidiretivas, vindas das áreas médicas, jurídicas, econômicas, sociais 
e de líderes comunitários, poderemos colaborar para diminuir e até erradicar estas tristes ocorrências em nosso meio.

\section{Discussão destas medidas preventivas}

Podemos pensar como é difícil quebrar barreiras sustentadas nos pré(conceitos), que separam os direitos e deveres de homens e mulheres, em todas as sociedades. Logo, mudar mentalidades, concernentes à igualdade destes direitos e ao respeito humano e social às diferenças, quaisquer que sejam elas, requer ainda um longo caminho a percorrer, tanto em países desenvolvidos, como nos países em via de desenvolvimento, como é o caso do Brasil.

Medidas preventivas que abranjam formação de pessoal, recursos de Redes Telefônicas de ajuda, criação de Centros Terapêuticos de Acolhimento, Mediação e Tratamento de Casais em Situação de Risco de Agressão, já se encontram muito desenvolvidos e em plena atuação, em países como o Canadá, França, Estados Unidos e Inglaterra (Oliveira et al., 1984; Rosen, 1989; Silva, 1989; Bowlby, 1990; Ministère de Secirité Publique, 1993; Ministère de la Justice, 1993, 1996; Raynor-Rinfret et al., 1994; Ministère du Travail et des Affaires Sociales, 1996). No Brasil, entretanto, carecemos destes serviços básicos, o que torna praticamente inviável falarmos em prevenção contra a violência conjugal, neste momento, em nosso país.

Apesar das verbas governamentais expressivas para combate à violência, em países desenvolvidos, e da presença de inúmeros programas de prevenção contra novos atos, os investigadores franceses e canadenses (Silva, 1989; Ministère de Secirité Publique, 1993; Ministère de la Justice, 1993; Raynor-Rinfret et al., 1994; Ministère du Travail et des Affaires Sociales, 1996) têm referido grandes dificuldades na prevenção e, mesmo, na assistência às vítimas e agressores. As mulheres, assim como ocorre no Brasil, notificam muito pouco, e quando isto ocorre, e é feito um boletim de ocorrência policial, elas também retiram as queixas rapidamente, em grande porcentagem de casos, e/ou não as sustentam, perante os juizes. Isto deve-se ao medo de represálias por parte de seus agressores, ou ao receio de passarem privações econômicas se os maridos forem presos, ou saírem dos seus lares (Silva, 1989; Raynor-Rinfret et al., 1994; Ministère du Travail et des Affaires Sociales, 1996). O tratamento aos agressores também é dificultoso, principalmente porque ele é compulsório, portanto, exigido pelo juiz como parte da penalidade. Um dos princípios básicos da psicoterapia é o desejo de se tratar; logo isto está, na maior parte dos casos, prejudicado no tratamento compulsório. Na maioria, os homens que agridem suas mulheres, não admitem ser violentos (Silva, 1989; Raynor-Rinfret et al., 1994; Ministère du Travail et des Affaires Sociales, 1996), e quando admitem, colocam nas características de personalidade de suas esposas e/ou no comportamento destas, o motivo de suas explosões coléricas.

A prevenção de ocorrências piores, ou de novas agressões, depende fundamentalmente da atenção dada às características das relações estabelecidas entre os casais, e da capacidade dos terapeutas mostrarem aos envolvidos que eles podem trabalhar as diferenças de outras formas, que não seja através da agressão. Isto tem sido muito realizado nos países mais desenvolvidos, e até mesmo no Brasil, através de técnicas psicoterápicas de mediação entre os casais.

Em nosso país, com os graves problemas econômicos e educacionais, com o alto índice de desemprego e de analfabetismo, assistimos, cada vez mais, a uma forte desestruturação das famílias e das instituições. O sistema público de saúde é um dos setores mais penalizados.

Isto tem repercutido sobre qualquer medida preventiva que queiramos implantar. Apesar disto vemos incansáveis profissionais, de diversas áreas psicossociais, empenhados em darem conferências, promoverem cursos, sensibilizarem os governos e a mídia, para este grave problema e suas conseqüências. Os órgãos emergencias de ajuda, tipo SOS-Mulher e Família, padecem de enormes dificuldades, em todo o Brasil (Beissman, 1994; Veja, 1998; Folha de São Paulo, 1998). Não temos linhas telefônicas suficientes de ajuda à distância, os órgãos que deveriam notificar e prestar assistência psicológica e social às vítimas e seus agressores, não estão conseguindo cumprir seus intentos. Assistimos a uma profunda desestruturação de muitos serviços brasileiros ligados a esta causa preventiva e assistencial, haja visto o exemplo de Campinas, onde órgãos como o SOS-Mulher e Família e o Crami (Centro de Atenção à Crianças e Adolescentes Maltratados), passam por enormes dificulda- 
des financeiras, perdendo profissionais gabaritados, com maior experiência neste tipo de atenção à mulher. A única casa de abrigo que a cidade possui funciona precariamente, não atendendo o mínimo do que necessitaria para cobrir as emergências da região. Vale salientar que Campinas é uma das cidades brasileiras mais atingidas por este tipo de violência contra a mulher (Beissman, 1994; Folha de São Paulo, 1998a,b). Concluímos, portanto, que a aplicação destas medidas preventivas ainda nos parece remota e extremamente difícil de ser valorizada em nosso país. As reformas sociais inexistem, e a vida humana nunca valeu tão pouco. A violência conjugal contra a mulher, é tão somente um dos profundos reflexos de todos estes "descasos", em que se encontra mergulhado o nosso país.

\section{Conclusões finais}

Analisando os vários artigos propostos no objetivo geral deste trabalho, concluímos que, tanto nos países desenvolvidos quanto no Brasil, há enormes dificuldades para pôr em prática medidas preventivas no combate à violência contra a mulher. Em países como Canadá,
França, Inglaterra e Estados Unidos, apesar da melhor estruturação dos serviços e dos programas de ajuda, as dificuldades têm suas raízes na complexidade do fenômeno e, essencialmente, nas pessoas envolvidas nos conflitos. As barreiras culturais, os fatores educacionais, a banalização dos comportamentos violentos, têm sido apontados por inúmeros autores (Silva, 1989; Raynor-Rinfret et al., 1994; Ministère do Travail et des Affaires Sociales, 1996), como ligados às dificuldades em prevenir e, mesmo assistir, terapeuticamente, às vítimas de comportamentos violentos no lar, assim como aos seus agressores. Em países em vias de desenvolvimento, como é o caso do Brasil, estes fatores se mostram agravados pela forte crise econômica mundial e local, tornando praticamente impossível a implantação de medidas eficazes no combate a estes tipos cruéis de agressão contra a mulher. Esta constatação está basicamente fundamentada e sustentada pelo aumento inexorável do número de casos em todo o Brasil. Urge que reunamos esforços em todas as esferas públicas e privadas, ligadas ao combate à violência, para ao menos conseguirmos amenizar este terrível quadro com implicações para a Saúde Pública brasileira.

\section{Referências}

Azevedo MA 1985. Mulheres Espancadas: A Violência Denunciada. Cortez, São Paulo, 176 pp.

Beissman DM 1994. Estudo Psicossocial de Homens Agressores de Mulheres Notificados na Delegacia da Mulher de Campinas, SP. Tese de Mestrado, Universidade Estadual de Campinas, Campinas, 223 pp.

Bowlby J 1985. Perda. Vol. 3, Cap.15, Martins Fontes, São Paulo.

Bowlby J 1990. Formação e Rompimento de Laços Afetivos. 2a edição, Martins Fontes, São Paulo, 165 pp.

Cabernite L 1982. O alcoolismo no Brasil e as dificuldades na área. Jornal Brasileiro de Psiquiatria31(2): 89-112.

Cabral MAA 1990. Estudo Descritivo de 62 Histórias de Vida de Presidiários Confinados em Cárceres Superpopulosos na Região de Campinas SP. Tese de LivreDocência, Universidade Estadual de Campinas, Campinas, 579 pp.

Cardin MS \& Azevedo BA 1991. Repercussões sociais do alcoolismo. Jornal Brasileiro de Psiquiatria 31(7): 365-370.

Carmichael L 1975. Distúrbios de comportamento na infância, p.77-227. In PH Mussen, Manual de Psicologia da Criança. E.P.U. 
Chesnais JC 1981. Histoire de la Violence. Robert Laffont, Paris, p.7-14.

Folha de São Paulo 1998a. Crime contra a mulher cresce em Campinas, 5 de julho, p. 7(5).

Folha de São Paulo 1998b. Campinas dobra agressões às mulheres, 18 de outubro, p. 3(3).

Folha de São Paulo 1998c. Desemprego impulsiona violência contra a mulher, 13 de abril, p. 3(2).

Folha de São Paulo 1998d. Violência doméstica empobrece a mulher. 8 de fevereiro, p. 1(14).

Hahner JE 1978. A Mulher no Brasil. Civilização Brasileira, Rio de Janeiro, 175 pp.

Kaplan HI \& Sadock BJ 1998. Sinopsis of Psychiatry. Behavioral Sciences/Clinical Psychiatry. 8th ed., Kathleen Courtney Millet, Baltimore, $1401 \mathrm{pp}$.

Lystad MH 1975. Violence at home: a review of the literature. American Journal of Orthopsychiatry 45(3): 328-345.

Ministère de la Justice 1993. Les actes du sommet de la justice. La justice: une responsabilité à partager. Tenu à Québec du 17 au 21 Février, 1992.

Ministère de la Justice 1996. Politique d'intervention en matière de violence conjugale. Prevenir, dépister, contrer la violence conjugale. Governement du Québec.

Ministère de la Securité Publique 1993. Rapport de la table ronde sur la prévention de la criminalité, pour un Québec plus sécuritaire: partenaire en prévention.

Ministère du Travail et des Affaires Sociales 1996. Violences conjugales: améliorer la prise en charge et les procédures judiciaires. Séminaire de formation sur les violences à l'encontre des femmes. Service des Droits des Femmes et Unesco, Paris.

Oliveira RD et al. 1984. A Violência Doméstica. Marco Zero, Rio de Janeiro, 64 pp.
Prado D \& Oliveira CF 1982. Relacionamento entre homem e mulher nas camadas de baixa renda: amor e violência. Jornal Brasileiro Psiquiatria 31(1): 6-10.

Raynor-Rinfret M et al. 1994. État de santé mentale d'un groupe de femmes violentées. Violence conjugale Recherches sur la violence faite aux femmes en milieu conjugal. Gäetan Morin, Québec, p.131-151.

Remschmidt H et al. 1991. Violência: causas e prevenção. Jornal Brasileiro de Psiquiatria 40(5): 273-278.

Rosen I 1989. Self-steem as a factor in social and domestic violence. Journal of Marriage and Family 40(4): $18-23$.

Sharp A et al. 1994. Comparaison de la situation de violence vécue par des femmes de milieu rural et de milieu urbain. Violence Conjugale. Recherches sur la violence faite aux femmes en milieu conjugal. Gäetan Morin, Quèbec, p. 33-71.

Silva AMC et al. 1982. Introdução ao estudo da sexualidade feminina. Jornal Brasileiro de Psiquiatria 31(5): 315-324.

Silva LMPF 1989. L'agression Physique Envers l'Epouseétude de Socipathologie Familiale Realisée dans la Societé Portugaise. Tese de Doutorado, Université de Lille, Paris, $352 \mathrm{pp}$.

Silva MV 1992. Violência contra a Mulher: Quem mete a colher? Cortez, São Paulo, p. 52-104.

Veja 1998. A face do silêncio: a violência doméstica atinge não apenas a mulher, mas toda a sociedade. 1 de julho, p. 80-87.

Wilson A 1985. The Family. Tavistock Publication, New York, p. 20-97.

Winnicott DW 1987. Privação e Delinqüência. Martins Fontes, São Paulo, p. 89-150.

Winnicott DW 1989. Tudo Começa em Casa. Martins Fontes, São Paulo, p. 63-78. 